\title{
“LIQUID JOB:" THE EMOTIONAL TEXT(URE) OF WORK UNCERTAINTY IN QUORA SITE
}

\author{
Concetta Papapicco
}

Department of Psychology, University of Bari Aldo Moro, Italy. concetta.papapicco@uniba.it

\begin{abstract}
The transformation of professional and productive systems involves an increase in inequality and instability in working careers. It is reflected in an increase in precarious and low-paid Workers, above all in the marginalized area, like Italy. We are witnessing of an increase in Internet users looking for information or asking for help in Question and Answer sites, as Quora Inc. In the study, it is hypothesized that the Italian workers, being more exposed to precarious working conditions, use online communities, like Quora, as spaces of mutual-help regarding the English workers. The research investigates how online sites become sharing environments for Italian and English workers and space to try resolving doubts. The methodology used is a mixed-methods approach: a Sentiment Analysis and an Emotional Analysis were carried out as a quantitative methodology; for the qualitative part, a Discourse Analysis was carried out. The quantitative analysis has an exploratory function, through which it has been highlighted the importance of a mixed methodology.
\end{abstract}

Keywords: Work Flexibility; Quora; Mixed-Methods Approach.

\section{INTRODUCTION}

The transformation of professional and productive systems involves an increase in inequality and instability in working careers. In many contexts, this is reflected by an increase in precarious and low-paid workers, subject to a lack of social protection and representation, in a downsizing of the social rights of workers and their families. Above all, the most "exposed" sectors of the job offer are those most at risk of unstable, precarious and poorly protected. But in contexts where it is more difficult to guarantee widespread institutional forms of protection and rights, the new risks of social insecurity concern a large slice of workers, even highly qualified ones, who are confronted with an increasingly fragmented and unstable employment system.

This situation of job deprivation is reflected in an increase in precarious and low-paid workers, above all in the marginalized areas, like Italy. On the other hand, the society is witness to an increase in Internet users looking for information or asking for help in question and answer sites, such as Quora Inc. This research investigates how online sites become sharing environments for Italian and English workers and a space to try to resolve doubts. In the study, I hypothesized that the Italian workers, being more exposed to precarious working conditions, use online communities, like Quora, as spaces of mutual help for the English 
workers. Specifically, the research question for this study is: Is Quora, as a $Q$ \& A site, becoming a space where workers could solve their doubts?

I used a mixed-methods approach (Creswell \& Creswell, 2017). I carried out a sentiment analysis and an emotional analysis as quantitative methodology (Pang \& Lee, 2008). For the qualitative part, I completed a discourse analysis (Van Dijk, 1985). The use of sentiment and emotional analysis in this study became fundamental to understand the positive, negative, or neutral polarity of the questions analyzed, the emotional involvement of these digitized professional identities seeking help in virtual communities. The quantitative analysis had an exploratory function, through which the importance of a mixed methodology was highlighted. The discourse analysis as a qualitative methodology had the functions, on the one hand, to deepen the quantitative data and, on the other hand, to bring out the relationship between the discourse, i.e. the interactions of Quora, at work and the power, which marginalizes workers.

\section{THEORETICAL FRAMEWORK}

The advent of globalization has led to the opening of the labor market. Companies now search for a niche by which to enter the market. This situation has influenced the flexibility of work as a result of phenomena such as offshore companies, joint ventures, outsourcing, and the request to workers for transversal skills and adaptation to new contexts involving vertical or horizontal workers transactions (Hall, 2002). The consequences of this "liquid" (Bauman, 2003) work involve different moments in the professional life of a human resource, from entry into the labor market to exit. Entry into the world of work is marked by job offers with requests for discursively unclear requisites, which can discourage the participation in selection processes by qualified candidates. Even professional life at the time of work flexibility is characterized by continuous changes.

In this panorama, especially in Italy, there is an increase in workers belonging to the "jobless" generation (Schreft \& Singh, 2003), or that portion of human capital without employment, inevitably cut off from the labor market. However, these professional identities are able to express themselves and generate meaning by talking about themselves and the professional reality in which they are immersed or would like to be part of. Taking into consideration that in order to understand the mechanisms of exclusion from work (Becker, 1964), the only balance of competences is no longer sufficient. At the same time, it becomes important to consider the detailed analysis of professional and transversal skills. It is 
necessary to ask about the social capital the person has, but also the heritage of cultural and relational premises that guide it, the events that have characterized it before, and oriented his way of being in (the working) world. It is necessary, therefore, to investigate the trajectories of meaning that the professional world assumes for each individual person and, for this reason, the relationship with the work must be narrated and must be listened to (Beck, 2000).

This generational exclusion was defined by Tsakloglou and Papadopoulos (2002) as a chronic cumulative disadvantage, understood as accumulation on the same subject of a plurality of social risks. The authors, therefore, study the processes and mechanisms of exclusion and localize them in different social spheres. These mechanisms are relational and multidimensional, and include institutional processes and mechanisms for protecting civil, social, and economic processes, such as the restructuring of the labor market. Moreover, these dimensions interact with each other. In more recent years, in terms of "disaffiliation" (Castel, 1995) they designate the outcome of a process of progressive exclusion from the general social context. It is, therefore, a problem of a dynamic nature because it implies that people are not excluded only because of their current situation, but also due to the lack of prospects for the future.

The job-less phenomenon has also been investigated in a political perspective. In this perspective, research problems are surrounded by how to use investment programs from the European Union (Gallino, 2014). But the fight against unemployment and poverty cannot be reduced to a simple economic and political intervention. Therefore, it is necessary to change the perspective on the job-less phenomenon, above all in marginalized areas, such as Italy. The intervention should be that of considering the generation without work as resources that could not only produce or invest, but workers, able to express themselves. From their narrations and discourses, it is possible to listen to the voices of marginalized workers to understand how they live this failed entry into the world of work, what their real professional needs are, and, consequently, how much they feel responsible for their careers. In this sense, their narration becomes a useful and non-invasive tool (Donati, 2001), to address a particularly delicate issue. It is a means through which the professional identity of the enunciator can emerge without constraints and concerns. In the age of work flexibility (Gallino, 2007), unemployment changes its face assuming the "human" face of discomfort of the single experience that is reflected in the construction of identity and in the sense of belonging. 
Work remains a primary element in defining social structure, as well as a central experience in individual biographies. Work is a fundamental activity of man which adds value to the world and to itself. The politician Trentin (1997) speaks of a work full of polyvalent capacities, capable of enriching the expertise of each worker. A tool, that of work, combined with knowledge because it is understood as a "commodity that must think" (Trentin, 1997, p. 17) that allows the person to adapt to the changes and the unexpected of flexibility. Here, the problem of the commodification of labor is contrasted with an image of the worker as a thinking subject, an actor in the production process that historically preserves the character of a central experience for individual self-determination. The work is the foundation of the personality because it allows feeling itself to be an actor on the social scene. Therefore, a lack of work deprives the person of a part of himself and of his social capital because it puts him in an uncomfortable relationship with others (Bourdieu, 1980; Putnam, 2001). And it is precisely by saying that these "invisible" workers in a country like Italy, that is not for young people nor even for experienced workers, describe themselves and give meaning to professional experience in terms of "slavery," "poverty," "devaluation of professionalism," and "discrimination" (Papapicco \& Quatera, 2019).

In addition to globalization, this employment insecurity was amplified even after the explosion of the Digital Revolution. If, on the one hand, digital (r)evolution has led to new demands in the labor market, especially following the introduction of increasingly smart instruments, but also following the emergence of generations of digital natives (Prensky, 2001) and adaptation the technologization of digital immigrants (Riva, 2014); on the other hand, the digital (r)evolution has created new spaces for comparison and support for 2.0 navigating workers, workers who are increasingly using technologies. An example is the "Questions and Answers" sites ( $Q$ \& A sites), virtual spaces in which users enter into public discussions, in which they can form networks of online and offline relationships. These virtual environments offer the opportunity to quickly get in touch with other Internet users and overcome spacetime barriers, typical of a face-to-face relationship. In fact, the connection becomes the new and privileged form of interaction for the Third Millennium man.

These virtual environments are characterized by a "transactive nature" (Mininni, 2010) by sharing processes and by negotiation practices. Since the 1990s, Internet users no longer passively consume the information made available by the web, but are now "active audiences" and "commentators" (Pulcini, 2006). These are users who modify or create existing content based on their own communication needs and do not fear to expose their 
opinions on blogs or social networks about specific issues. Furthermore, these innovative technologies have provided different opportunities for collaboration and creation of user networks, generating virtual spaces in which each user is the author of signification practices. It emerges, therefore, that the Digital Revolution has contributed by making the world of work more uncertain. However, some virtual spaces, such as virtual communities, can be spaces where workers can manage their uncertainties through mutual assistance.

\section{QUORA AS A WAY TO FACE WORK UNCERTAINTIES}

Following the Digital Revolution and the introduction of new media, virtual communication shapes the whole experience of the world. Among this, the working sphere, where selfpositioning is mediated through social and professional identity, becomes "digital professional identity" (Perry, 2012). This inevitably influences entry into the world of work, a challenge people also face through communication mediated by computer environments. In this landscape, there has been an increase in Internet users looking for information or asking for help in $Q$ \& A sites. Participation in these virtual communities is motivated by interest in particular topics and in the behavior of reciprocity and pro-sociality. In these virtual spaces, users produce digital content that can be understood as a psycho-discursive practice, modulated in the format of the "question/answer" exchange. One of the most popular question and answer sites is Quora, Inc (https://it.quora.com/). Founded in 2009, it is a virtual space that is based on sharing; users can discuss any topic inserted in thematic macroareas. A common fundamental aspect, which falls within the policy of all $Q$ \& $A$ sites, is moderation by an administrator appointed for each discussion, who has the task of enforcing the online behavioral code, called netiquette (Mintu-Wimsatt et al., 2010). The administrators can intervene on three fronts:

1. Positive/negative votes: Administrators can evaluate the answers based on relevance or usefulness. In this way, the quality of the posted content is guaranteed, since the more positive votes an answer receives, the greater its "online visibility" in user feeds (Morales et al., 2014). Conversely, if an answer receives negative votes, it is omitted and will not be shown in the feeds.

2. Reports: Administrators can report plagiarism, harassment, spam, and conflicts. This keeps the content that does not respect netiquette under control (Paul, Hong, \& Chi, 2012).

3. Change suggestions: Administrators can offer suggestions to improve an answer, proposing changes. The proposed changes are also visible to the original author of the answer and can be approved and published or rejected, maintaining a logic of collaboration (Calefato et al., 2015). 


\section{HYPOTHESIS}

There is a high unemployment rate in Italy and therefore greater uncertainty in job searches and management of job interviews. This job uncertainty contributes to doubts in workers that result in questions in online communities, since workers begin to take advantage of all the opportunities of the web. Starting from the hypothesis that Italian workers are more uncertain than other workers in the world, it is possible to understand what the doubts of the Italian workers are in the $Q \& A$ formatted interactions. Specifically, the research question for this study is: Is Quora, as a $Q$ \& A site, becoming a space where workers could solve their doubts? Starting from the fact that work is a cultural phenomenon and that in Italy work is experienced as "slavery" (Papapicco \& Quatera, 2019), the research aims specifically to verify how the doubts of Italian workers change compared to workers in the rest of the world.

\section{METHODOLOGY}

One of the most discussed topics on Quora, Inc. concerns the work sphere that counts 1,300 questions in the Italian section and 500 questions in English. The choice to compare the Quora section dedicated to work with questions in Italian compared to the questions in English is because English is a lingua franca, used by more workers in the world. Quora provides a direct link with the profile of the user who asked or answered the question. This option allowed me to assess users' location. Regarding data collection, questions I chose in Italian were in the Italian section on work. I chose questions in the international section on work in English. In the two sections about work (Italian and English), I based data collection on a keyword search. I used "job seeking," "job interview," "job search," and "job and cv" as keywords for English the section and "ricerca del lavoro," "colloquio di lavoro," and "selezione del personale" for the Italian section. These keywords refer to a job search, interviewing, or writing curriculum.

In this study, I focused on the section of questions and answers posed by Italian workers in the Italian language and questions in English posed by non-Italian users on topics concerning the work environment. The result of the search allowed me to collect 36 questions and 81 responses in Italian and 35 questions and 86 answers in English. I chose more recent questions with more views and comments during 2019.

I used a mixed-methods approach. As noted previously, I carried out a sentiment analysis and emotional analysis for the quantitative analysis (Pang \& Lee, 2008). This is a useful 
methodology to extrapolate from the texts a polarity (positive, negative, or neutral) and to consider the emotion prevalent in the textual extracts. I used two software: SentiStrength for the sentiment analysis and the Tone Analyzer of the IBM group for emotional analysis. The operation mode of these software is that of matching the text in input with their inner vocabularies of words. It offers as output a data of total emotion on the base of a scale with a score lower than 0.50 , equal to 0.50 and higher than 0.50 ; the significant values are those higher than 0.50 .

Although synonyms, "sentiment" and "emotion" do not express the same thing. A "sentiment" is an opinion or view. The term "emotion," refers to a strong feeling deriving from one's mood. Conducting both a sentiment and an emotional analysis is conducting two distinct evaluation methods of people's moods. They both aim to better understand the readers and give insights about their emotional responses, but sentiment analysis aims to catch the general feel or impression of people. It does not focus on the specific, articulate emotions. The automatic method of sentiment analysis goes back as output the polarity of a positive, negative, or neutral text. It relies on a simplified binary system, where the nuances of emotions do not count. Contrary to sentiment analysis, emotional analysis relies on a more sophisticated and complex system. The emotions detected are the five basic emotions or the innate and not social emotions (Ekman \& Lama, 2008). These basic emotions, or even defined primary, detected by the software are joy, fear, sadness, disgust, and anger.

For the qualitative data, I completed a discourse analysis (Van Dijk, 1985) to bring out the relationship between discourse at work, i.e. the interactions of Quora, and the context of enunciation which marginalizes workers, i.e. the flexibility-working context. Discourse analysis is a theoretical and methodological resource to face many social problems which considers discourses, i.e. Quora interactions about work context, as social practices, bringing out from them the critical and ideological point of view. The quantitative analysis allowed for the extraction of sentiment and emotions focused more on the questions, to understand which are the most important doubts and emotional involvement of the workers in a context of work flexibility and if there will be differences between Italian and English questions. The qualitative analysis, instead, focused on questions and answers. I analysed the questions and answers qualitatively through the analysis of the discourse (Mininni \& Manuti, 2017). The discourse, in this case, is the social construction of reality. For the analysis, I interpreted the individual discourses, annotating recurrences of expressions, verbs, subjects employed. The goal, therefore, was to trace constellation of terms, phrases, references, metaphors, 
allusions acting together, but at different structural levels, to give body to a certain cultural theme, such as that of job uncertainty.

The quantitative analysis had an exploratory function with the task of detecting the limits of the results of Natural Language Processing (NLP) software. For example, for questions in Italian a negative score was attributed to "sùbito," that is "immediately" in English, which is confused with "subito," which translates as "suffer." For English questions, however, there was a more precise recognition of words and meanings linguistically. At the same time, the output returned did not seem to read the context of the statement. One of the greatest limitations of automatic systems of quantitative analysis is the excessive simplification of basic data or models on which artificial intelligence is designed. This makes it difficult to engage with variables important for analysis, such as context. For this reason, the combination of sentiment and emotional analysis was an efficient methodology, but it was advisable to integrate quantitative and qualitative methods.

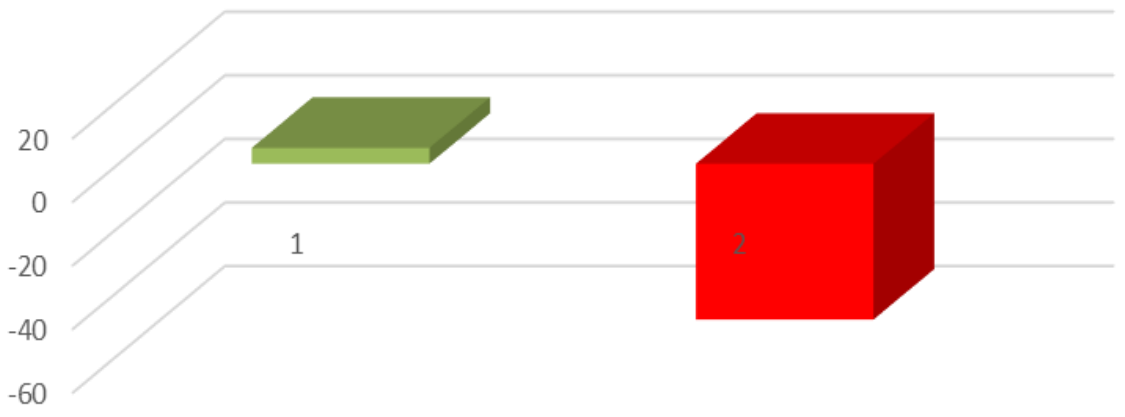

Figure 1. Total Sentiment Analysis Output

The qualitative method, specially the discourse analysis, aimed to go deeper into the subject in question to collect information about people's motivations, thoughts, and attitudes. Additionally, I was able to favor the subjectivity of the participants involved, taking into account both the historical and working moment, in the specific case of the study. Additionally, discourse analysis allowed me to consider the individual context of enunciation, in this case a virtual one. 


\subsection{Quantitative Results}

I first conducted a sentiment analysis SentiStrength, from which I obtained a predominantly positive sentiment for Italian questions and a predominantly negative sentiment for English questions, as shown in Figure 1 above. Figure 1 shows the prevalence and intensity of Italian questions characterized by positivity. As shown in the figure, the positivity value is +5 and it is at left colored in green. On the right is the negative value of -49 for the questions in English. The red color represents the strong negativity of the polarity. The scores are based on the automatic calculation of the weight given to the words of the internal vocabulary of the software and the text collected.

In the case of Italian workers' questions, the software calculates as strongly positive questions such as, "Quali sono alcuni segnali che stai superando alla grande il colloquio di lavoro?" which has a sentiment value of +2 . This translates to "What are some signs that you are overcoming the job interview?" For this example, the software indicates the terms "overcoming" and "great" and positive. For the questions asked in English, instead, the score of strong negativity depends on terms like "mistakes," inserted in a context of positive enunciation, as in the following example, "What are the biggest career mistakes to avoid?" which has a sentiment value of -3 . In this example, the user asks for advice on what career error to avoid. The reference to the "career" is interesting, in how much it delineated the possibility of "choice" of the non-Italian workers to undertake more career paths. The positivity of the questions in Italian, compared to those posed in English, denotes a different signification and use of these virtual spaces, since the positivity is an indicator of a clear desire to ask for help in these online environments and, consequently, confidence in the possibility to resolve their uncertainties thanks to otherness.

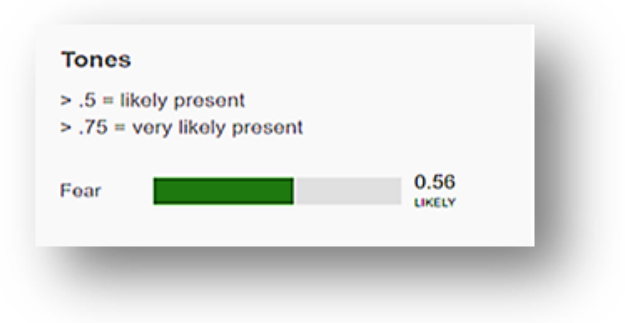

Figure 2. Results of the Emotional Analysis of Fear 
Starting with these data, to assess which emotions are hidden behind the sentiment of the questions, I conducted an emotional analysis with the IBM Tone Analyzer software. The results I obtained from the emotional analysis on questions with negative sentiment do not agree in all cases with the outputs of sentiment analysis. In some of the Italian questions, there is a prevalence of neutrality and joy, in which it is possible there is a sense of hope for the worker who seeks advice. In others, one of the emotions resulting as output is fear, as shown in Figure 2 above and the following example, "I social network sono la nuova frontiera per ottenere un colloquio di lavoro? È davvero diventato inevitabile mischiare la vita privata con il lavoro?" This translates to "Are social networks the new frontier for obtaining a job interview? Has it really become inevitable to mix private life with work?" with a sentiment value of +1 . In this particular case, the extract is fraught with fear, linked to the fact that recruiters can view the potential candidate's social profile to test his skills. There is a fear of limiting the freedom of the worker in managing a social page. On the contrary, the prevailing emotionality underlying English questions, with negative sentiment, is sadness, as shown in Figure 3 below. As an example, the question "How can I figure out what I really want to do with my life after college?" has a sentiment value of -1 .

The results of the tone analyzer software are more consistent with the outputs of sentiment analysis for English questions than Italian questions and show a prevalence of sadness, as shown in Figure 3. Other differences in the questions of Italian and English workers reside in issues of doubt and the different types of questions. From the questions collected in Italian and English, I created two word clouds. A word cloud is tool to visually and more effectively show consumption data. Word clouds are commonly used in marketing. In this case, the word cloud is a clarifying means, useful to immediately see the topics most discussed in Italian and English questions, as shown in Figure 4 below.

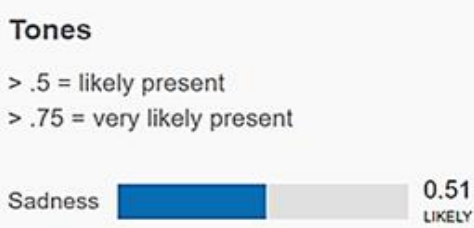

Figure 3. Results of the Emotional Analysis of Sadness

The word cloud is a way to visually illustrate the results of the sentiment and emotional analysis. At the center of the word cloud are the most discussed topics, which in the case of 
the questions in English concern how one can become "rich." In the case of the questions in Italian, the theme most addressed concerns how it is possible to find a job, "trovare un lavoro." The repetition of the main words in the word cloud is an indicator of how often those topics are recurrent. The different dimension of the occurrences indicates the centrality of that topic in the context of the question posed.

As you can see from the word cloud in Figure 4 below, the doubts of Italian workers, "consumers of uncertainties", concern the need to obtain useful advice to find a job or to deal with negative situations such as dismissal or unemployment. This is contrary to the word cloud of questions in English which address issues related more to career opportunities or how to acquire skills. In the Italian word cloud, the recurring words in the questions are "find a job," "fired," and "interview."

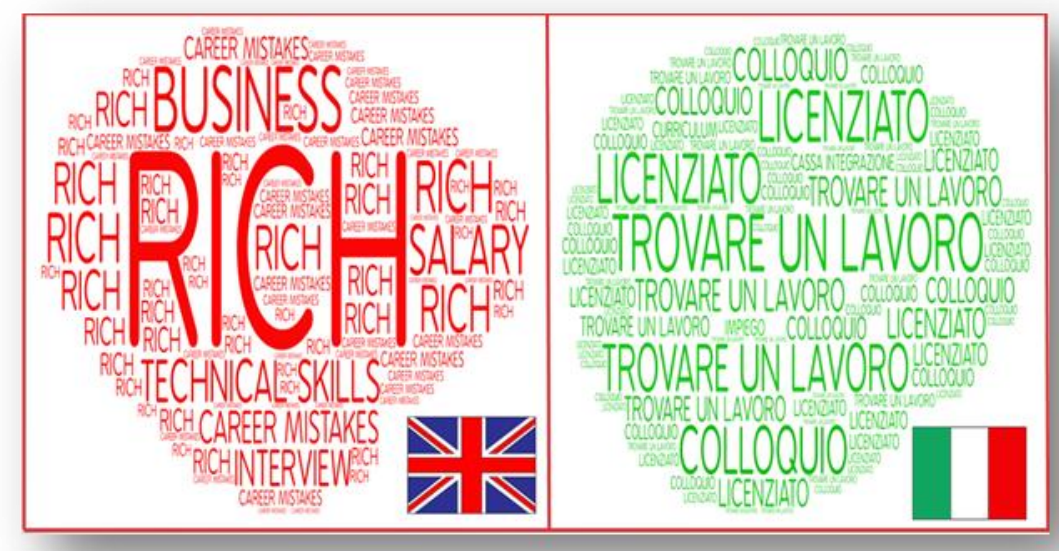

Figure 4. Word Cloud about Italian and English Job Questions

Additionally, there are different types of questions. Using the taxonomy of Morris et al. (2010), I traced three types of questions with respective examples in Italian and English summarized in Table 1 below.

Table 1. Types of Questions from Workers on Quora, Starting from the Taxonomy of Morris et al. (2010)

\begin{tabular}{lll}
\hline Question Type & English & Italian \\
\hline Recommendation (1) & How do I pass a behavioural interview & $\begin{array}{l}\text { Qual è il modo migliore descriversi in } \\
\text { un colloquio? }\end{array}$ \\
Opinion (2) & $\begin{array}{l}\text { What job should I get if I want to be Come posso migliorare il mio } \\
\text { rich? }\end{array}$ & $\begin{array}{l}\text { Curriculum se non lavaro da anni? } \\
\text { Factual Knowledge (3) job seeker, what is something Quali sono I metodi consigliati per } \\
\text { you have done that has helped you get cercare lavaro in Italia? } \\
\text { more interviews? }\end{array}$ \\
\hline
\end{tabular}


Table 1 indicates that I found recommendation questions, opinion questions, and questions about factual knowledge in both Italian and English. The most common types of questions were recommendation and opinion questions. To answer either requires subjective information. While an opinion question requires an assessment of a specific item, a recommendation request is an open request for suggestions. Questions on factual knowledge, on the other hand, have objective answers. In this regard, an additional clue comes from the answers and comments to the answers: the Italian replies have a more analytical style and are provided by company experts, including recruiters or workers managers. On the contrary, the answers to the English questions include expressions such as "in my opinion..." or "for me..." They are based on personal experience and are therefore less detailed and formal. The use of less informal expressions in English answers may be because of cultural differences due to greater homogeneity of the places of origin of workers who use the English language in online communities. However, the fact that the moderators of the Italian Q\&A spaces evaluate the answers provided by experts in the sector as reliable would justify the need to clarify the situation of uncertainty at work.

In addition to entering the workforce, a moment of uncertainty for Italian workers is also the maintenance of a job. This last aspect emerges as a real fear of the Italian workers at the risk of losing, almost unjustifiably, the work. This was indicated in the emotional analysis. The positivity of the sentiment, however, shows how these spaces, although virtual, constitute a place of mutual help where you can both manage doubts and uncertainties and overcome the fear of the working future.

\subsection{Qualitative Findings}

Discourse analysis findings indicate the presence of mitigation strategies in greater numbers in Italian questions. These are rhetorical strategies used to attenuate the content of discourses. Mitigation is useful in courtesy communications where there is a netiquette. Mitigation strategies can also show a sense of uncertainty of the speaker, reducing the responsibilities of the interlocutors, but facilitating the achievement of different communication objectives. It is therefore functional for prudent interactional development, to avoid risks of refusal, censorship, or conflict, typical of failure to comply with the netiquette of the $Q$ \& $A$ sites. With these strategies, users also aim to achieve both cognitive and emotional detachment from the complete linguistic act. A particular type of frequent mitigation I detected during the discourse analysis of Italian questions is the "lenitive 
mitigation" (Caffi, 2007). These are mitigations that work to reduce the intensity of discursive acts, decreasing the potential threat to themselves and avoiding rejection. This type of mitigation strategy occurs with the use of a hypothetical period because users tend to imagine a possible situation in which they build a premise before asking the actual question. For example, consider the question "Se sapessi di venire licenziato in due settimane, cosa faresti?" which translates to "If you knew you would be fired in two weeks, what would you do?"

Another mitigation strategy is the use of the conditional, as shown in the example, "Sarebbe opportuno cambiare l'argomento nei colloqui dopo averne fatti tanti senza successo?" tranlsating to "Would it be appropriate to change the subject in the talks after having made so many without success?" Another strategy is the use of indirect acts such as the preliminary questions, used to express a concept in a veiled way. This can be seen in the question, "Quali sono le aziende e/o mansioni lavorative che si possono svolgere da casa in modo autonomo? Che cosa mi consigliate?" which tranlsates to "What are the companies and/or job duties that can be performed independently from home? What do you recommend?"

There is also a frequent use of modal verbs, such as "having" and "can," which activate the presupposition functions. These verbs express uncertainty and, if used conditionally, indicate the weakness of contextual clues. This is clear from the example, "Come posso fare affinché sia il mio primo impiego a 'trovare' me e non viceversa?" which translates to "How can I make it my first job to 'find' me and not vice versa?" The use of mitigation strategies would justify positive sentiment in Italian questions since attenuated, courteous rhetoric is used. But, it highlights that there are more uncertainty indicators than English questions. Thus, in the flexibility of work, the $Q$ \& $A$ sites become an opportunity to manage insecurities by asking for help from people that are more experienced or those who are simply in the same situation of uncertainty.

The greater use of lenitive mitigation strategies in the Quora interactions of Italian workers shows a greater level of uncertainty especially at the time of entry into the world of work. This is because the worker is required more specializations, a predisposition to mobility, an attention to soft skills, and above all the ability to be responsible for career advancement and training. Finally, leaving the world of work or a specific professional context is more frequent both among young workers and between older workers. Unemployment, therefore, changes 
its face and undermines the very foundations of society. It reveals the fragility of labor policies but, at the same time, it becomes a propitious occasion for a global rethinking of society. Today, well-armored people are falling into the limbo of the worker both from the educational point of view and from the acquired professional experience.

\section{DISCUSSION}

From the quantum-qualitative results it emerges that the research hypothesis is verified: Quora, as a virtual community of questions and answers, becomes a place where workers can solve their doubts. The positivity of the sentiment of the questions in Italian are an indicator of a sense of hope in the search for information through this virtual medium (Harper et al., 2008). This is explained more by the answers to the questions that, in the section in Italian, are provided by people who work in the context of selection and then respond in a detailed and formal way. The questions posed by Italian workers present occurrences of mitigators, which can be interpreted as discursive markers of uncertainty. Unlike British workers for whom the questions have no uncertainty markers, the answers are given informally and in less detail.

With regards to the type of questions, there is no difference between the questions asked in Italian and those in English. The types of questions found are recommendation, opinion, and factual knowledge. Different, however, are the topics addressed in the questions of Italian and English workers. The doubts of Italian workers concern the need to obtain useful advice to find a job or to deal with negative situations such as dismissal or unemployment. This is contrary to questions in English, which address issues related more to career opportunities or how to acquire skills. It is precisely in this difference that the doubts of Italian workers fit in and this becomes a real cultural phenomenon, where flexibility of work is no longer an opportunity, but a constraint (Bertolini, Torrioni, 2015).

It emerges, in fact, that unemployment is not just an economic problem, it is the impossibility of re-acting. This opportunity, especially in the Italian case, is favored by mutual aid in the virtual community of Quora.

\section{CONCLUSION}

The transformation of professional and productive systems involves an increase in inequality and instability in working careers. The inequality and instability are reflected in an increase in precarious and low-paid workers in marginalized areas, such as Italy. Specifically, the advent 
of globalization and the Digital Revolution's explosion have led big transformations. We are witnessing of an increase in Internet users looking for information or asking for help in $Q \& A$ sites. A well-known Q \& A site is Quora, Inc. It is a virtual space that is based on sharing. Users can discuss any topic inserted in thematic macro-areas. This research investigated how Quora, Inc. becomes a sharing environment for marginalized workers and a space to try resolving doubts. In particular, I focused on Italian workers. I used a mixed methods approach using sentiment analysis, emotional analysis, and discourse analysis (Pang \& Lee, 2008; Van Dijk, 1985). The prevalence of positive sentiment and emotions of joy and fear in the Italian questions indicate a sense of hope. Qualitatively, I detected a higher presence of mitigation rhetorical strategies than questions in English, confirming the presence of uncertainties in Italian workers.

\section{REFERENCES}

Bauman, Z. (2003). Intimations of postmodernity. London.

Beck, U. (2000). La società del rischio. Verso una seconda modernità [The society of risk. Towards a second modernity]. Carocci.

Becker, G. (1964). Human Capital. Columbia University Press.

Bertolini, S., Torrioni, P. M. (2015). La flessibilità come opportunità e vincolo. Un approccio multidisciplinare [Flexibility as opportunity and constraint. A multidisciplinary approach]. CELID.

Bourdieu, P. (1980). Le capital social: notes provisoires [Social capital: provisional notes]. Actes de la recherche en sciences sociales, 31(1), 2-3. https://www.cairn.info/le-capital-social--9782707148049-page-29.html

Caffi, C. (2007). Mitigation. Elsevier.

Calefato, F., Lanubile, F., Raffaella, M., \& Merolla, N. N. (2015). Success factors for effective knowledge sharing in community-based question-answering. Proc. of the International Forum on Knowledge Asset Dynamics (2015), 1431-1441. http://collab.di.uniba.it/fabio/wp-content/uploads/sites/5/2014/05/IFKAD_final1.pdf

Castel R., (1995). Les métamorphoses de la question sociale [The social issue metamorphosis]. Fayard.

Creswell, J. W., \& Creswell, J. D. (2017). Research design: Qualitative, quantitative, and mixed methods approaches. Sage.

Donati, P. (2001). II lavoro che emerge. Prospettive del lavoro come relazione sociale in una economia dopomoderna [The work that emerges. Perspectives of work as a social relationship in a post-modern economy]. Bollati Boringhieri.

Ekman, P, \& Lama, D. (2008). Emotional awareness: Overcoming the obstacles to psychological balance and compassion. Holt.

Gallino, L. (2007). II lavoro non è una merce. Contro la flessibilità [Work is not a commodity. Against flexibility]. Laterza.

Gallino, L. (2014). Vite rinviate. Lo scandalo del lavoro precario [Lives postponed. The scandal of precarious work]. Laterza.

Hall, D. T. (2002). Protean careers in and out of organizations. Sage. 
Harper, F. M., Raban, D., Rafaeli, S., \& Konstan, J. A. (2008). Predictors of answer quality in online Q\&A sites [Conference paper]. SIGCHI Conference on Human Factors in Computing Systems, Florance, Italy. https://dl.acm.org/doi/10.1145/1357054.1357191

Mininni, G. \& Manuti, A. (2017). A rose is more than a rose...the diatextual constitution of subjects and objects. De Gruyter Mouton, 37(2), 243-263. https://doi.org/10.1515/text-2017-0005

Mininni, G. (2010). The method of dialogue: Transaction through interaction. Integrative Psychological and Behavioral Science, 44(1), 23-29. https://doi.org/ 10.1007/s12124-009-9111-1

Mintu-Wimsatt, A., Kernek, C., \& Lozada, H. R. (2010). Netiquette: Make it part of your syllabus. MERLOT Journal of Online Learning and Teaching, 6(1), 264-267. https://jolt.merlot.org/vol6no1/mintu-wimsatt_0310.pdf

Morales, A., Borondo, J., Losada, J. and Benito, R. (2014). Efficiency of human activity on information spreading on Twitter. Social Networks, 39, 1-11. https://doi.org/10.1016/j.socnet.2014.03.007

Morris, M. R., Teevan, J., \& Panovich, K. (2010). What do people ask their social networks, and why?: A survey study of status message q\&a behavior [Conference paper]. SIGCHI conference on Human factors in computing systems, Atlanta, Georgia, USA. https://dl.acm.org/doi/proceedings/10.1145/1753326

Pang, B., \& Lee, L. (2008). Opinion mining and sentiment analysis. Foundations and trends in information retrieval, 2(1-2), 1-135. http://www.cs.cornell.edu/home/llee/omsa/omsa.pdf

Papapicco, C. \& Quatera, I. (2019). Disoccupati a tempo pieno! Come occupare i lavoratori dimenticati [Full-time unemployed! How to occupy forgotten workers]. In Croce, C., Prevete, R., Zucca, A. (Eds.), Porte Girevoli. Contributi di ricerca e buone pratiche sul lavoro marginale e le nuove vulnerabilità sociali [Revolving Doors. Research contributions and good practices on marginal work and new social vulnerabilities] (pp. 267-287). Editori Fondazione Giangiacomo Feltrinelli.

Paul, S. A., Hong, L., \& Chi, E. H. (2012). Who is authoritative? understanding reputation mechanisms in quora [Conference paper]. Collective Intelligence, Cambridge, Massachusetts, USA. https://arxiv.org/abs/1204.3724

Perry, C. W. (2012). Constructing professional identity in an online graduate clinical training program: Possibilities for online supervision. Journal of Systemic Therapies, 31(3), 53-67. https://doi.org/10.1521/jsyt.2012.31.3.53

Prensky, M. (2001). Digital natives, digital immigrants part 1. On the horizon, 9(5), 1-6. https://www.marcprensky.com/writing/Prensky\%20-\%20Digital\%20Natives,\%20Digital\%20Immigrants\%20\%20Part1.pdf

Pulcini, E. (2006). Click TV. Come Internet e il digitale cambieranno la televisione [Click TV. How the Internet and digital will change television]. Franco Angeli.

Putnam, R. (2001). Bowling alone: The collapse and revival of american community. Simon \& Schuster.

Riva, G. (2014). Nativi digitali: crescere e apprendere nel mondo dei nuovi media [Digital natives: growing and learning in the world of new media]. Bologna.

Schreft, S. L., Singh A. (2003). A closer look at jobless recoveries. Economic Review, 88(2), 45-73. https://ideas.repec.org/a/fip/fedker/y2003iqiip45-73nv.88no.2.html

Trentin, B. (1997). La città del lavoro: sinistra e crisi del fordismo [The city of work: the left party and the crisis of Fordism]. Feltrinelli.

Tsakloglou P., \& Papadopoulos, F. (2002). Aggregate level and determining factors of social exclusion in twelve European countries. Journal of European Social Policy, 12(3), 211-225. https://doi.org/10.1177/0952872002012003394

Van Dijk, T. A. (1985). Handbook of discourse analysis. London: Academic Press.

Sitography https://it.quora.com/ 